\title{
EXPERIMENTAL DEFINITION OF THE VISCOUS FRICTION COEFFICIENTS FOR MOVING LiNKS OF MULTILINK UNDERWATER MANIPULATOR
}

\author{
Vladimir F. Filaretove ${ }^{\mathrm{a}, \mathrm{b}}$, Aleksandr Yu. Konoplin ${ }^{\mathrm{a}, \mathrm{b}}$ \\ ${ }^{a}$ Far Eastern Federal University, Sukhanova 8, Vladivostok 690950, Russia \\ ${ }^{b}$ Institute for automation and control processes Far Eastern Branch of RAS, Radio5, Vladivostok 690041, Russia
}

\begin{abstract}
Today majority of the underwater vehicles are equipped by multilink manipulators. The manipulator, moving in water, renders the significant force and torque influences on an underwater vehicle. These influences displace the vehicle from its initial space position. The values of said influences are proportional to viscous friction coefficients of the each manipulator link. Accuracy of the underwater vehicle stabilization in a given space point directly depends on accuracy of definition of the required coefficients. In this paper the experimental approach allowing to define the viscous friction coefficients and also its dependence on the tilt angle of link to the fluid flow is described. Studies were performed in aerodynamical tunnel. The offered approach is based on a momentum-transfer method and has high accuracy and also simplicity of experiment realization. For confirmation of experiment results the sea tests were performed.
\end{abstract}

Keyword: viscous friction coefficient; aerodynamical experiment; aerodynamical tunnel; multilink manipulator; underwater vehicle
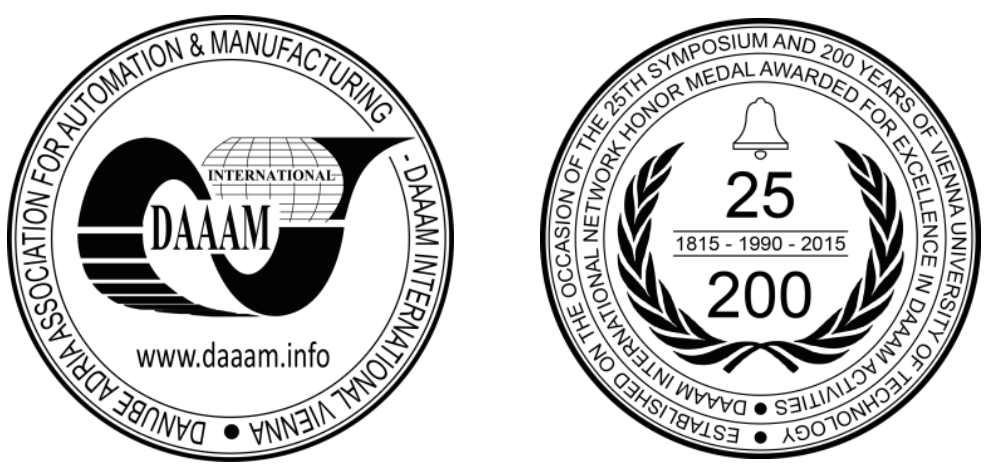

This Publication has to be referred as: Filaretov, V[ladimir] \& Konoplin, A[leksandr] (2016). Experimental Definition of the Viscous Friction Coefficients for Moving Links of Multilink Underwater Manipulator, Proceedings of the 26th DAAAM International Symposium, pp.0762-0767, B. Katalinic (Ed.), Published by DAAAM International, ISBN 978-3-902734-07-5, ISSN 1726-9679, Vienna, Austria

DOI: $10.2507 / 26$ th.daaam.proceedings. 106 


\section{Introduction}

Today most of the manned and telecontrolled underwater vehicles (UV) are equipped with multilink underwater manipulators (UM), and the quality of performance of the underwater operations depends on the accuracy and speed of movements of such manipulators. However, an UM, moving in the water environment, is subjected to significant force and torque influences. These influences are caused by the inertial and gravitational forces, and also forces determined by interaction of the working manipulator and viscous environment [1]. The specified influences displace the UV, operating in a hang mode, from its initial space position. Thus the accuracy of the manipulator's work is reduced. The above effects complicate the qualitative performance of most of the manipulation tasks.

The known systems for automatic stabilization of the UV in a hang mode near the operating objects [2-4] allow us to compensate for the negative force and torque influences from the working UM. These influences are calculated in real time. The values of these dynamic influences are proportional to the viscous friction coefficients of each UM link at the arbitrary spatial movements of a manipulator in water. These coefficients can be determined experimentally and depend on a geometrical form of the links, specific features of their surface and also on the tilt angle of a link to the fluid flow. It is obvious that the accuracy of the UV stabilization in a given space point directly depends on the accuracy of definition of the required coefficients.

The known scientific works noted significant interest in solving the problem of precise determination of these coefficients. Work [3] describes the results of experimental determination of the viscous friction coefficients arising when the cylindrical UM links move normally to an oncoming water flow. The analytical dependence of the viscous friction coefficient on the tilt angle of a link to the fluid flow was obtained in the work [5]. But this dependence is very approximate. The experimental method for defining of dependence of the said coefficients on the tilt angle of a link to the fluid flow was described in work [6]. However, the obtained values of these coefficients can be used only for the two-links UM having a special links connection. Herewith, the equations, used for calculation of coefficients, include only the components of linear speeds of the segments of UM links. These components are directed perpendicular to the axis of the cylindrical links. Using these equations, we can calculate the viscous friction coefficients only when UM links move perpendicularly to the oncoming flow of fluid.

The implemented analysis of the existing approaches and methods shows that today the task of creation of a universal approach to the experimental definition of the viscous friction coefficients of each multilink UM link still has to be solved.

\section{Statement of problem}

The objective of this paper is the development of an approach to solving of the assigned task, allowing us to experimentally determine the viscous friction coefficients with the help of an aerodynamic experiment. Values of these coefficients are necessary for calculation of the force and torque influences on an UV from a moving multilink UM with the purpose of their subsequent compensation by means of the vehicle thrusters in process of the UV stabilization in water environment.

\section{Specifics of determination of the force impacts on the UM link, moving in the water environment}

There is no analytical determination of the viscous friction coefficients of the UM links, moving in the water environment, due to their complex dependence on the parameters of movement of these links, and many other physical factors. These coefficients should be determined experimentally for calculation of the force and torque influences on an UV from a working multilink UM.

It should be noted, that the Reynolds number becomes less than $10^{3}$ for the UM links having cross-sectional diameter of $0.1 \mathrm{~m}$ and at their movements in the water environment at speed less $0.01 \mathrm{~m} / \mathrm{s}$. However, during execution of most of a working operations the UM links have much greater speeds at which there are significant dynamic influences on an UV. Therefore, according to the recommendations outlined in work [1], the influence of viscous environment on these links may be neglected at Reynolds numbers less than $10^{3}$. But in some cases it is advisable to use the viscous friction coefficients, given in works [1,7], which do not depend on the tilt angles of links to the fluid flow. In the experimental determination of the coefficients during the movement with the speed at which the Reynolds numbers were in the range of $10^{3}<\operatorname{Re} \leq 2 * 10^{5}$, each link was represented as a homogeneous cylindrical body, on which a counter water flow acted. In this case the force, acting of this link, has a quadratic dependence on the speed of link's movement [1]:

$$
F=0.5 \rho k s v^{2}
$$


where $k$ and $v$ are the viscous friction coefficient and the linear speed of the translational motion of the UM link, respectively; $\rho$ - the fluid density; $s$ - the projected area of a side surface of the link on a plane which is perpendicular to the vector $v$.

As it is noted in work [7], in this range of Reynolds numbers, at the strictly transverse motion of bodies, having a cylindrical shape, the viscous friction coefficient is practically unchanged. That is $k=$ const. Since each end of each UM link is connected either with an adjacent link, or with the working tool, or with an UV, the ends of these links do not affect the value of the coefficient $k$, which is not dependent on the lengths of UM links. Therefore, at experimental determination of $k$, the link should be considered as endlessly long. However, at tilting of the link to water flow, the value $F$ will vary in proportion to the length of the link, in accordance to (1).

Value of the coefficient $k$ for an endlessly long link can be determined with help of aerodynamical experiment. Herewith, it is necessary to observe a similarity of the UM link and its model in accordance with Reynolds number [8]. The offered approach is based on the momentum-transfer method [9] and is characterized by high accuracy, simplicity and convenience in realization of experiments. Using this method, the desired coefficient $k$ can be calculated by the formula:

$$
k=\frac{2}{D} \int_{a}^{b} \sqrt{\frac{P_{1}-p_{1}}{P_{0}-p_{0}}}\left(1-\sqrt{\frac{P_{1}-p_{0}}{P_{0}-p_{0}}}\right) d \hat{Z}=\frac{2}{D} \int_{a}^{b} \varphi(\hat{Z}) d \hat{Z}=\frac{2 S}{D}
$$

where $D$ is the characteristic size the UM link; $P_{0}$ and $p_{0}$ - the values of total pressure and static pressure, respectively, determined by pneumatic measuring instrument which located before the model of link in the undisturbed flow; $P_{1}$ and $p_{1}$ - the values of total pressure and the static pressure in the wake turbulence of the UM link, respectively (these values are determined by a special pneumatic measuring instrument, which moves along an axis $\hat{Z}$, which perpendicular to the speed vector $v$ of an oncoming flow and lying in a horizontal plane, at the vertical position of UM link at the fixed distance $L$ ' from link's surface); $a$ and $b$ - the limits of a wake turbulence along an axis $\hat{Z}$; $S$ - the area bounded by the experimental curve $\varphi(\hat{Z})$. These designations are shown in Fig. 1. At an arrangement of the UM link at an angle $Q$ to the incoming flow $D=d / \sin Q ; s=l d \sin Q$, where $d$ and $l$ are diameter and length of a link, respectively.

\section{Description of the aerodynamic experimental equipment}

The experimental research was performed in the aerodynamic tube AS-1. Scheme of the developed experimental equipment is shown on Fig. 1.

Model of the cylindrical UM link 6 was made of aluminum alloy and geometrically similar to the real link with diameter $d=0.05 \mathrm{~m}$. This model is installed in the working area of AS-1 in the center of airflow. For any values of angle $Q$ the ends of a link 6 do not fall into airflow and do not cause the interference and vortex formation in working area of an aerodynamic tube. All displacements of a link and measuring devices were performed in a rectangular coordinate system (SC) $X Y Z$, where axis $X$ coincides with the direction of the airflow speed vector $v, Y$ is a vertical axis, $Z$ is an axis component of the right-handed SC. The center of SC XYZ is located in the center of working area of aerodynamic tube, where speed of airflow is stable and well-known.

In the experimental study the pneumometric method of fixation of full pressure and static pressure in airflow by receivers 4 and 9 was used. Measurements of these parameters were performed by "U" - type laboratory liquid differential manometers 5 and 8. Pressure receiver measures values $P_{l}$ and $p_{l}$ in airflow behind model. For the different values of an angle $Q$ the distance from model to receiver was $L^{\prime}=0.02 \mathrm{~m}=$ constant. The receiver moved along axis $\hat{Z}$ , which is parallel to an axis $Z$ of SC $X Y Z$ and creates with $Z$ a horizontal plane. Displacements of receiver were produced by the traversing gear 7 , which has a coordinate scales $X^{\prime} Y^{\prime} Z^{\prime}$. 


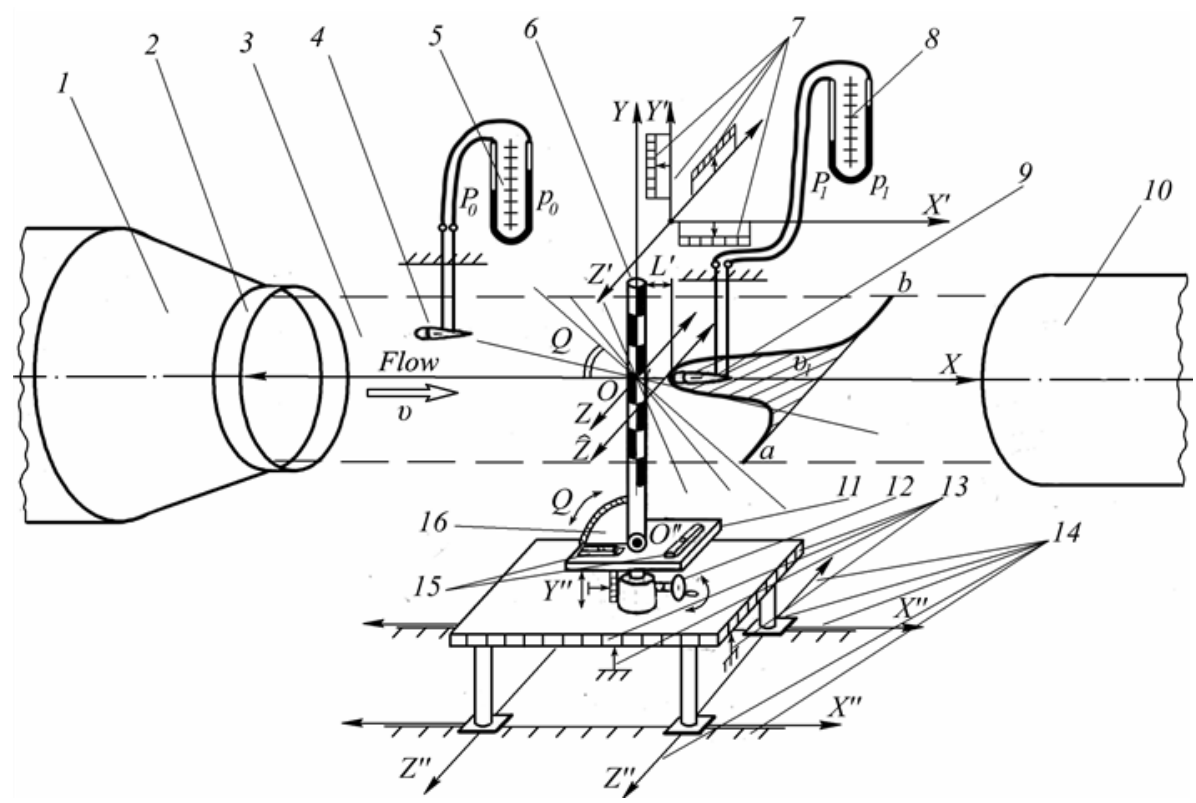

Fig. 1. Scheme of the experimental equipment

1 - confuser; 2 - nozzle; 3 - working area; 4 and 9 - receivers of total and static pressure; 5 and 8 - "U" - type differential fluid micromanometers; 6 - model of UM link; 7 - traversing gear; 10 - diffuser; 11 - desktop; 12 - hoist of desktop; 13 - movable platform with the coordinate scales; 14 - rail platform; 15 - alignment tools of desktop; 16 scale of angular coordinates

For increasing of measurement precision the axis of cylindrical link 6 was always directed through point $O$ for any values of an angle $Q$ (see Fig.1). For alignment of the cylinder axis with the point $O$ the link moved in the horizontal and vertical planes by the moving platform with coordinate scales $X^{\prime \prime} Y$ ' $Z$ '.' The scale of angular coordinates 16 controlled an angle $Q$. The alignment tools of desktop 15 provided position of the desktop 11 strictly in a horizontal plane. After installation of the cylindrical link to the desired position for every value of an angle $Q$, the values $P_{l}$ and $p_{l}$ was measured by receivers 4 and 9 , which moved from the start position behind link 6 to the direction along axis $\hat{Z}$ with step of $0.005 \mathrm{~m}$ to values $+(-) 0.07 \mathrm{~m}$ and with step of $0.01 \mathrm{~m}$ to values $+(-) 0.17 \mathrm{~m}$.

The general view of experimental equipment is shown on Fig. 2, where position of model of UM link at an angle $Q=45^{\circ}$ to oncoming airflow is shown.

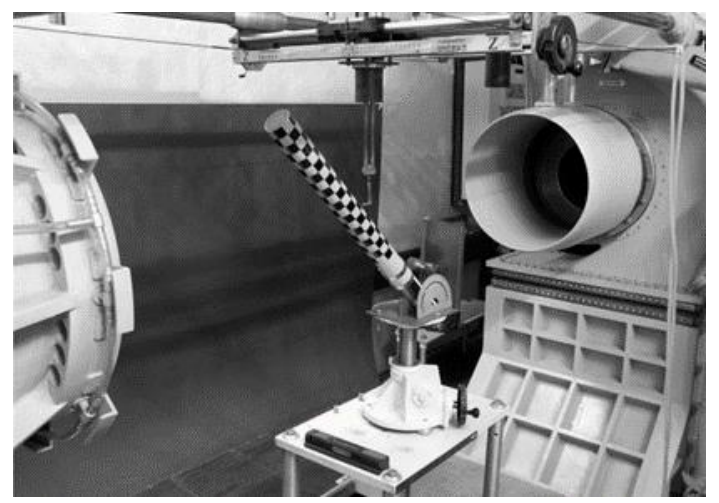

Fig. 2. The general view of aerodynamic experimental equipment

\section{The results of experimental studies}

In real time scale for each position of the link 6 the profile of airflow speed $v_{1}$ behind the link was built with help of formula:

$v_{1}=\sqrt{\frac{2 g \xi\left(P_{1}-p_{1}\right)}{\rho}}$ 
where $g=9.81$ is the conversion factor from mm of water column to $\mathrm{N} / \mathrm{m}^{2} ; \xi=0,9 \div 1$ is the correction factor of pressure receivers. The atmospheric barometric density of air $\rho$ was determined prior to the measurements and remained unchanged in the process of these measurements.

The speed $v$ of the undisturbed flow in the aerodynamic tube was $26 \mathrm{~m} / \mathrm{s}$. Therefore, when $Q=90^{0} \div 12^{0}$ the Reynolds numbers were in the range of $9 * 10^{4}<\operatorname{Re} \leq 4.3 * 10^{5}$. The values of the coefficient $k$ for each position of link 6 were calculated by the formula $(2)$, and the area $S$, limited by experimental curve $\varphi(\hat{Z})$, was calculated by graphical integration in the developed computer program.

Fig. 3 shows the family of the speed curves when $Q$ changes from $90^{0}$ to $12^{0}$. The experimental curves confirm the general picture of the turbulent wake, consistent with the hypothesis of turbulence of Taylor [10].

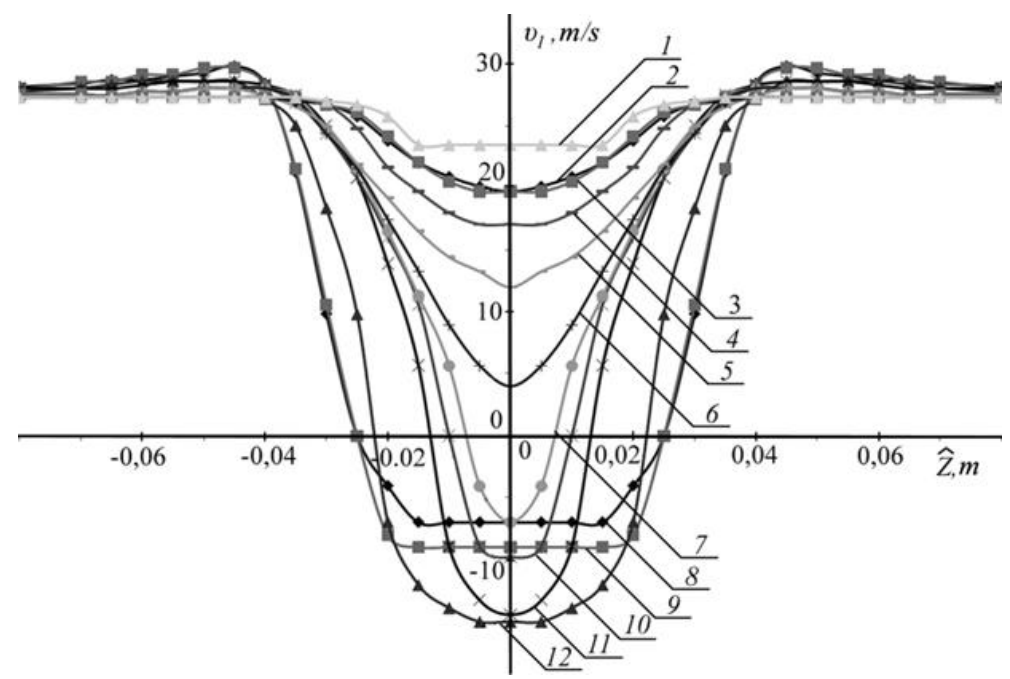

Fig. 3. The experimental curves of airflow speed

$1-\mathrm{Q} 0=120 ; 2-\mathrm{Q} 0=170 ; 3-\mathrm{Q} 0=220 ; 4-\mathrm{Q} 0=270 ; 5-\mathrm{Q} 0=300 ; 6-\mathrm{Q} 0=350 ; 7-\mathrm{Q} 0=380 ; 8-\mathrm{Q} 0=900 ; 9-\mathrm{Q} 0$ $=750 ; 10-\mathrm{Q} 0=400 ; 11-\mathrm{Q} 0=450 ; 12-\mathrm{Q} 0=600$

Fig. 4 shows the experimentally obtained dependence of the coefficients $\mathrm{k}$ from an angle Q. Using of this coefficient in the equation (1) allows as to calculate the force of viscous friction acting on the cylindrical UM link moving in the water environment. As a result, it will allow us to provide accurate stabilization of UV in hang mode and effective implementation of manipulation operations [4, 11, 12].

For confirmation of the results of the aerodynamic experiment the sea tests were done. Herewith, the values of the required coefficients received in the sea and aerodynamic experiments appeared very close.

\section{Conclusion}

This paper describes the solution of the problem of experimentally determination the viscous friction coefficients with the help of an aerodynamic experiment. The offered approach is based on the momentum-transfer method and is characterized by high accuracy, simplicity and convenience in realization of experiments. For realization of the experimental researches in an aerodynamic tunnel an experimental adjustment was developed. With the help of this adjustment the dependence of the viscous friction coefficients on the tilt angle of a link to the fluid flow was determined. Values of these coefficients are necessary for calculation of the force and torque influences on an UV from a moving manipulator with the purpose of their subsequent compensation by means of the vehicle thrusters.

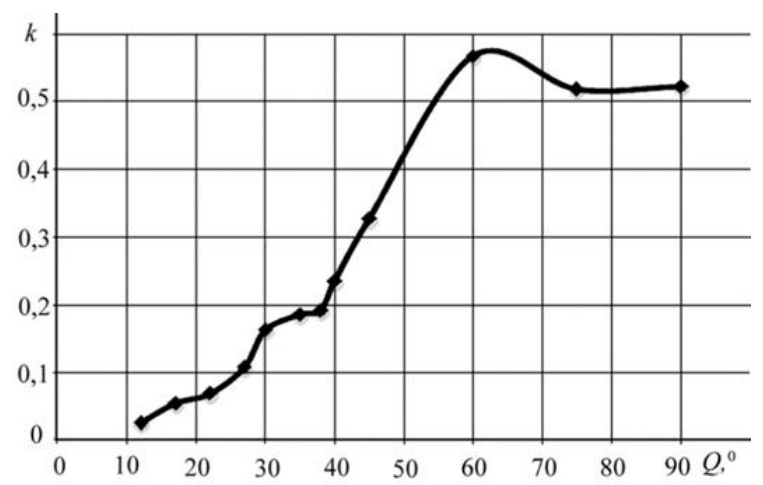

Fig. 4. The graph of dependence of the coefficients $k$ from an angle Q 


\section{Acknowledgements}

Paper was supported by Ministry of education and science of Russia (state contract 1141).

\section{References}

[1] P. Coiffet, Robot Technology: Interaction with the environment. Kogan Page Ltd. London. 1983. 290p.

[2] V.F. Filaretov, Yu.K. Alekseev, A.V. Lebedev, Control system of underwater vehicle / Edited by Filaretov V.F. M.: Krugliy god, 2001. 288 р. (В.Ф. Филаретов, Ю.К. Алексеев, А.В. Лебедев, Системы управления подводными роботами / Под ред. В.Ф. Филаретова. - М.: Круглый год, 2001. 288 с.)

[3] McLain T.W., Rock S.M., Lee M.J. Experiments in the coordinated control of an underwater arm/vehicle system. Autonomous Robots, vol. 3, 1996. no. 2-3, pp. 213-232.

[4] V.F. Filaretov, A.Yu. Konoplin, Automatic stabilization system of underwater vehicle in hang mode when multilink manipulator working. Part 2// Mehatronika, avtomatizacija, upravlenie. 2014. №7. p. 29-34. (В.Ф. Филаретов, А.Ю. Коноплин, Система автоматической стабилизации подводного аппарата в режиме зависания при работающем многозвенном манипуляторе. Часть 2 // Мехатроника, автоматизация, управление. 2014. №7. С. 29-34.)

[5] Tarn T. J., Shoults G. A., Yang S. P. A dynamic model of an underwater vehicle with a robotic manipulator using Kane's method. Autonomous Robots, V.3, no. 2-3, 1996. pp. 269-283.

[6] Leabourne K.N., Rock S.M. Model Development of an Underwater Manipulator for Coordinated Arm-Vehicle Control. OCEANS '98 Conference Proceedings. V.2. Oct 1998. pp. 941 - 946.

[7] V.P. Korpachev, Theoretical basis of water transport timber: Textbook for high schools. - M.: Publishing house “Akademija Estestvoznanija”, 2009. - 237 р. (Корпачев В.П. Теоретические основы водного транспорта леса: Учебное пособие для вузов. - М.: Издательство «Академия Естествознания», 2009. - 237 с.)

[8] B.N. Yurev, Experimental aerodynamics. Part 1. Theoretical basis of experimental aerodynamics. M.-L., 1939. 302 p. (Юрьев Б.Н. Экспериментальная аэродинамика. Часть 1. Теоретические основы экспериментальной аэродинамики. М.-Л., 1939. -302 с.)

[9] A.K. Martinov, Experimental aerodynamics. - М.: 1958. - 348 р. (Мартынов А.К. Экспериментальная аэродинамика - M.: 1958.- 348 с.)

[10] G.N. Abramovich, Theory of turbulent jets. M.: ECOLIT, 2011. -720 р. (Абрамович Г.Н. Теория турбулентных струй. - М.: ЭКОЛИТ, 2011. - 720 с.)

[11] Filaretov V.F., Konoplin A.Yu. System of Automatically Correction of Program Trajectory of Motion of Multilink Manipulator Installed on Underwater Vehicle // Procedia Engineering, Vol 100, 2015. pp. 1441-1449.

[12] Hildebrandt M., Christensen L., Kerdels J., Albiez J. Realtime motion compensation for ROV-based tele-operated underwater manipulators. OCEANS 2009 - EUROPE. Bremen. May 2009. pp. 1-6. 